Gdańsk 2020, Nr. 42

https://doi.org/10.26881/sgg.2020.42.01

\title{
30 Jahre Danziger Germanistik. Statt eines Vorwortes
}

Im Sommer 1989 öffnete die Danziger Germanistik ihre Pforten. Die in diesem Band dokumentierte wissenschaftliche Konferenz „Dreißig Jahre germanistische Forschung in Polen und Deutschland 1989-2019“ wurde im Juni 2019 aus Anlass dieses 30. Jubiläums organisiert. Jubiläen haben etwas Magisches, sie sind ein guter Anlass, zurückzublicken, Bilanz zu ziehen, Fragen zu stellen, das Erreichte zu präsentieren, den Blick aber auch nach vorne zu richten und Perspektiven zu zeigen.

Das Jahr 1989 war eine unvergessliche Zäsur: Am 4. Juni fanden in Polen die ersten freien bzw. teilweise freien Wahlen statt und wenige Monate später fiel die Berliner Mauer, die damals eine geteilte Welt symbolisierte. Infolge dieser Ereignisse wurden die Weichen für das deutschpolnische Verhältnis neu gestellt. Die Organisatoren der Danziger Konferenz haben deshalb den Zeitraum von 1989 bis 2019 zur Reflexion über die Entwicklung der Germanistik in Polen und Deutschland vorgeschlagen. Wir wollten den historischen Hintergrund zwar nicht überbewerten, denn die Forschung hängt auch von anderen Faktoren ab. Es war eine Zeit, in der sich der kulturwissenschaftliche Diskurs weiterentwickelt hat und die germanistische Forschung mehr und mehr interdisziplinären Charakter annahm. Neben den klassischen Forschungsrichtungen wie Linguistik oder Literaturwissenschaft spielte die Interdisziplin Übersetzungswissenschaft eine immer größere Rolle. Die politische Wende von 1989 hat dennoch einen Paradigmenwechsel in der polnischen Germanistik eingeleitet, die sich für neue Themen öffnete und einen breiten Dialog mit der Germanistik im nun vereinigten Deutschland anstrebte. Später kamen neue Forschungsansätze wie Inter- und Transkulturalität, Studien zur kontrastiven Diskurs- und Medienlinguistik, zur Migrationsliteratur, Gender Studies, Theaterwissenschaft, postkoloniale Studien u. a. hinzu. Auf der Jubiläumstagung wurden einzelne dieser neuen Forschungsrichtungen in den Blick genommen und ihr Potential an Einzelanalysen erprobt.

Die Germanistik in Polen hat die Aufgabe, deutsche Sprache und Literatur zu vermitteln. Zu Beginn der 1990er Jahre bestand ihre Hauptaufgabe in der Ausbildung von Deutschlehrern für das polnische Bildungswesen. Nach der politischen Wende stieg in Polen die Bedeutung der westeuropäischen Sprachen enorm. Auch die Germanistik hat sich zunächst sprunghaft entwickelt. Innerhalb von etwa 15 Jahren war jedoch der Bedarf an Deutschlehrern weitgehend gedeckt. Diese Situation stellte die Germanistik vor neue Herausforderungen.

Zusätzlich kam es nach 1999 auch in Polen durch den Bologna-Prozess zu einer tiefgreifenden Umgestaltung des Studiums. Das bisherige fünfährige Magisterstudium wurde durch das dreijährige Bachelor- und das zweijährige Masterstudium ersetzt. Dabei sollte bereits 
der Bachelorabschluss den Einstieg in das Berufsleben ermöglichen. Dieses System hatte seinen Preis. Die berufsorientierten Fächer wurden auf Kosten des Deutschunterrichts und der wissenschaftlich ausgerichteten Lehrveranstaltungen ausgebaut. Gleichzeitig entstanden neue Spezialisierungen. So wurde auch in Danzig die Translatorik entwickelt, d. h. eine Spezialisierung für Übersetzer und Dolmetscher. Im Jahre 2016 ging das Institut einen Schritt weiter und eröffnete die Spezialisierung Business und Wirtschaft, die mit fachspezifischen Lehrfächern auf die berufliche Tätigkeit im Bereich der Wirtschaft vorbereitet. Ein weiteres Angebot sind die Deutschlandstudien, die das Institut für Germanistik seit 2012 gemeinsam mit dem Institut für Geschichte der Universität Gdańsk durchführt.

In den Curricula der Germanistik und der Deutschlandstudien finden sich darüber hinaus neue Lerninhalte: u. a. regionale Geschichte und Kultur sowie die Problematik der deutschpolnischen Grenzregion. Die Geschichte der früheren deutschen Ostprovinzen Schlesien, Pommern und Ostpreußen war in der polnischen Öffentlichkeit bis vor 30 Jahren ein Tabu. Heute ist sie Teil von Lehre und Forschung. Die deutschen Spuren werden besonders an den Universitäten erforscht, die auf dem Gebiet des ehemaligen deutschen Ostens liegen, wie Gdańsk/Danzig, Wrocław/Breslau, Szczecin/Stettin, Opole/Oppeln, Zielona Góra/Grünberg, Olsztyn/Allenstein. Dies ist eine deutliche Tendenz in der polnischen germanistischen Forschung der letzten 30 Jahre. So haben die Danziger Germanisten dem in ihrer Stadt gebürtigen Schriftsteller und Nobelpreisträger Günter Grass zwei internationale Konferenzen, 2007 und 2012, gewidmet und 2017 ein Günter-Grass-Lexikon veröffentlicht. Sie erforschen die multinationale Erinnerungskultur in der Region und die lokale Kulturgeschichte, u. a. die Geschichte des deutschen Stadttheaters und der Presse. Ein interessantes Forschungsfeld ist die vielfältige deutsche Literatur aus bzw. über Ostpreußen. Die neueren Studien über die deutsche Literatur im deutsch-polnischen Grenzraum sind anders als in den 1960er und 1970er Jahren meistens durch Unvoreingenommenheit gekennzeichnet. Die regionale deutsche Literatur und Kultur sind deshalb in der polnischen germanistischen Forschung gut aufgehoben.

Das Institut für Germanistik der Universität Gdańsk zählt heute 29 im Bereich der Lehre und Forschung tätige Kolleginnen und Kollegen, die zur Zeit etwa 300 Germanistikstudenten im Bachelor- und Masterstudium ausbilden. Für die Germanistik ist Danzig ein interessanter Studienort. Dies lässt sich u. a. mit dem Hinweis auf die historische Rolle der deutschen Sprache und Kultur in der Stadt und ihrer Umgebung erklären. Aber auch für die Forschung ist die Stadt attraktiv. Sie besitzt Archiv- und Bibliotheksbestände, die (freilich nicht ohne empfindliche Einbußen) den letzten Krieg und die nahezu totale Zerstörung der Innenstadt überlebten, darunter die vor mehr als 400 Jahren gegründete und seitdem sorgfältig erweiterte Stadtbibliothek, heute Bibliothek der Polnischen Akademie der Wissenschaften. Danzig ist deshalb prädestiniert für Forschungsprojekte mit historisch-regionalen Aspekten wie auch für inter- und transkulturelle Studien.

Von diesem Forschungsprofil zeugen neben Monographien und Sammelbänden auch viele Einzelstudien, die u. a. in der seit 1993 herausgegebenen germanistischen wissenschaftlichen Zeitschrift Studia Germanica Gedanensia veröffentlicht wurden. Bisher sind 41 Bände dieser Zeitschrift erschienen. In den vorliegenden Band wurden literaturwissenschaftliche Beiträge der Jubiläumstagung aufgenommen; die linguistischen Texte erscheinen im Band 43. 
Wir danken dem Prorektor für Forschung und dem Dekan der Philologischen Fakultät der Universität Gdańsk für ihre finanzielle Unterstützung. Der Johann-Gottfried-HerderStiftung sind wir für die Mitfinanzierung nicht nur dieser Tagung, sondern vieler anderer wissenschaftlicher und didaktischer Projekte der Danziger Germanistik, zu großem Dank verpflichtet. Ein weiterer Dank gilt dem Generalkonsulat der Bundesrepublik Deutschland, das ebenfalls zum Gelingen der Jubiläumskonferenz beitrug. Den Autorinnen und Autoren sowie dem Universitätsverlag sei für die gute Zusammenarbeit gedankt.

Danzig, im September 2020

Die Herausgeber

Literatur zur Geschichte der Germanistik an der Universität Gdańsk

Brandt, Marion (2018): Zur Geschichte und zum wissenschaftlichen Profil der Germanistik an der Universität Danzig (Gdańsk). In: Geschichte der literaturwissenschaftlichen Germanistik in Polen. Bd. 3: Institutionen und Rabmenbedingungen. Hrsg. v. Wojciech Kunicki und Marek Zybura. Leipzig: Universitätsverlag, 125-139.

Kątny, Andrzej (2012): Historia i teraźniejszość germanistyki gdańskiej w zarysie. In: Orbis Linguarum 38, Dresden, Wrocław, 487-497.

Kątny, Andrzej / Ossowski, Mirosław (2013): Zur Germanistik an der Universität Gdańsk. In: Tribüne. Zeitschrift für Sprache und Schreibung 1/ 2013, 32-40. 